\title{
- Case Article
}

\section{Frontal sinus mucopyelocele with intracranial and intraorbital extension}

\author{
Gupta $\mathrm{S}^{1}$, Goyal R${ }^{2}$, Shahi $\mathrm{M}^{3}$ \\ People's Hospital, People's College of Medical Science and Research Centre, Bhopal (MP) INDIA \\ ${ }^{1}$ Associate Professor, Department of Ophthalmology, ${ }^{2}$ Associate Professor, Department of \\ Otorhinolaryngology and ${ }^{3}$ Assistant Professor, Department of Neurosurgery
}

\begin{abstract}
This case is related to a 52-year-old lady with proptosis, diplopia and diminution of vision due to a mass lesion in upper medial quadrant of the orbit. CT scan revealed a well defined mass in basi-frontal area with intra-orbital and intracranial extension. On exploring it was found to be mucopyocele of the frontal sinus. Surgical excision was done by external approach. The symptoms and signs resolved completely within a week. Frontal sinus mucopyoceles are benign and curable. Early recognition and management of them is of paramount importance because they can expand and cause local, orbital or intracranial complications.
\end{abstract}

Keyword: Mucocele, mucopyocele, paranasal sinuses, visual loss, proptosis

\section{Introduction}

Mucopyocele is a chronic, expanding, mucosa-lined lesion of the paranasal sinus with retention of mucous and pus. Though benign, they have a tendency to expand by eroding the surrounding bony walls that displaces and destroys structures by pressure and bony resorption (Peral et al 2006). Symptoms and signs of frontal mucopyeloceles include pain, swelling, proptosis, diplopia and loss of vision. Intracranial extension may lead to meningitis, meningoencephalitis, pneumocephalus, and brain abscess. The treatment is surgery by external open approach.

\section{Case Report}

A 52 year-old-lady presented with a progressive bulging of right eye with deterioration of vision for three months. The globe was pushed forwards, downwards and outwards by a nontender diffuse, non-pulsatile mass in upper medial quadrant of the orbit (Fig-1).

Received on: 06.05.2010 Accepted on: 12.11.2010 Correspondence and reprint request to:Dr Saroj Gupta, MD Associate Professor, People's Hospital,

People's College of Medical Science and Research Centre, Bhopal (MP), India

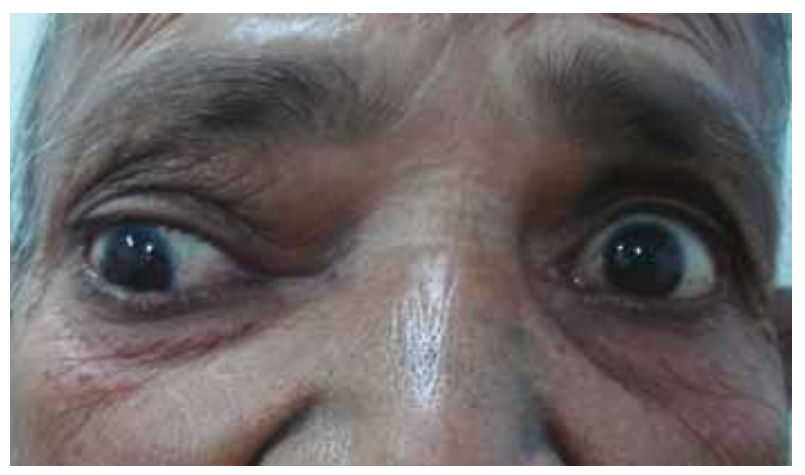

Fig-1: Clinical photograph of the patient showing proptosis with lateral displacement of eye ball on right side.

On examination, vision in right eye was 20/200, whereas in left eye it was normal. There was no history of headache, epistaxis, trauma or seizures. Computed tomography of orbit and sinuses revealed a well defined expansive mass in basifrontal area, isodense, non-enhancing, measuring $3.6 \times 3.5 \times 2.4$ $\mathrm{cm}$ with bony erosions. It extended into anterior cranial fossa and was in direct contact with the meninges. It also invaded the orbit from superomedial aspect and displaced the eyeball downwards and outwards. (Fig-2) Fine needle aspiration cytology was inconclusive. 


\section{NEPiop}

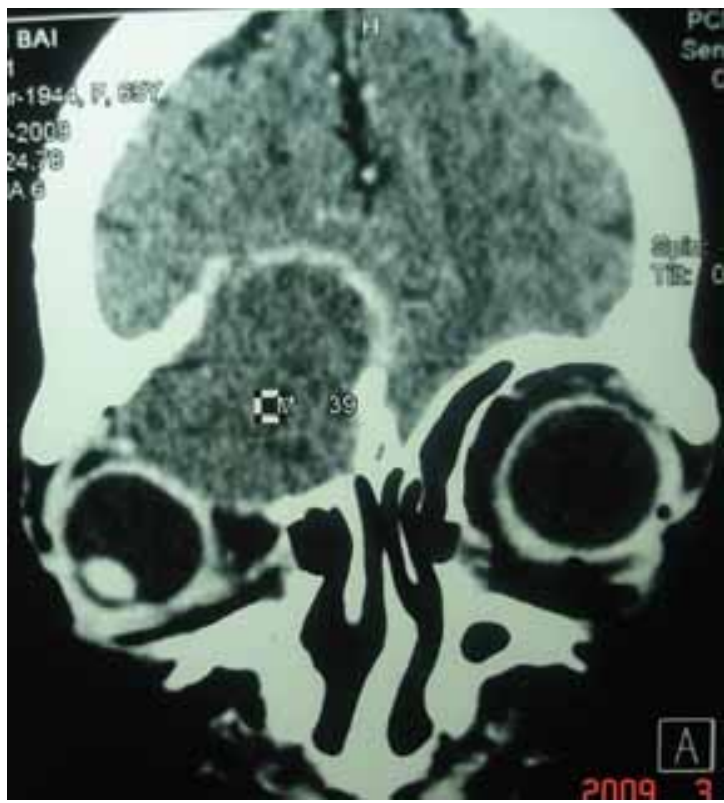

Fig-2: CT scan orbit showing a mass lesion on right side with extension into the cranial cavity as well as in orbit, displacing the eyeball downwards and outwards

Based on clinical and radiological findings a probable diagnosis of mucocele of frontal sinus with intracranial and intraorbital extension was made. Differential diagnosis included - dermoid cyst, histiocytoma, fungal or tubercular infection or a neoplastic lesion. The patient was operated by a surgical team comprising a neurosurgeon, an ENT surgeon and an ophthalmic surgeon. To reach the lesion, an external surgical approach was used. Incision was given just below the medial half of right eyebrow. On exploring it was found to be a mucopyocele of the frontal sinus. Thick mucopurulent discharge was sucked out and the mucocele was completely excised. Proptosis and globe displacement resolved completely within a week (Fig-3). The vision also improved to $20 / 20$ in the right eye.

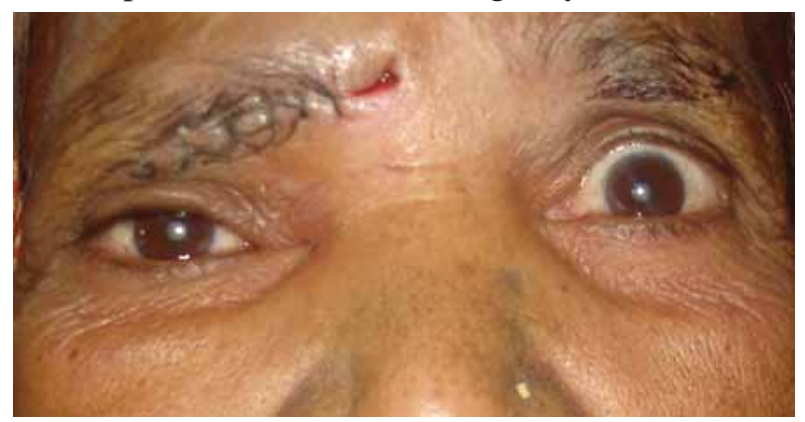

Fig-3: Clinical photograph of the patient showing complete resolution of proptosis after surgical treatment

\section{Discussion}

Mucocele of para nasal sinuses are caused by obstruction of sinus ostium. The closure of ostium may be secondary to infection, allergy, trauma, benign or malignant neoplasm (Rajan et al 2007). The incidence of mucocele of sinuses causing unilateral proptosis has been variable depending upon the special interest of the investigators. Frontal sinus mucocele is the most common $(65 \%)$ among the paranasal sinus mucoceles (Tan et al 2005). There is a greater risk of optic neuropathy and visual loss with sphenoid sinus and Onodi cell mucoceles because of their proximity to the optic nerve. However, fronto-ethmoidal mucoceles are not benign and may compromise vision, especially if a posterior ethmoid sinus is involved, or if treatment is delayed and secondary infection has ensued to form a pyocele (Loo et al 2009). Therefore, management of paranasal mucoceles requires early diagnosis, prompt treatment and multidisciplinary co-operation.

\section{References}

CSH Tan, VKY Yong, LW Yip, S Amirth (2005). An unusual presentation of a giant frontal sinus mucocele manifesting with a subcutaneous forehead mass. Ann Acad Med Singapore; 34:397- 3984

Loo JL, Looi AL, Seah LL (2009). Visual outcomes in patients with paranasal mucoceles. Ophthal Plast Reconstr Surg; 25(2):126-9.

Peral-Cagigal B, Barrientos-Lezcano J, FlorianoBlanco R, García-Cantera JM, Sánchez-Cuéllar LA, Verrier- Hernández A(2006). Frontal sinus mucocele with intracranial and intraorbital extension. Med Oral Patol Oral Cir Bucal;11:e527-30.

Rajan K V, Santhi T (2007). Frontoethmoidal mucocele with orbital and intracranial extension. Indian journal of otolaryngology and head \& neck surgery; 59(4):363-365.

Source of support: nil. Conflict of interest: none 